\title{
L4-L5 Intervertebral Space
}

National Cancer Institute

\section{Source}

National Cancer Institute. L4-L5 Intervertebral Space. NCI Thesaurus. Code C142296.

The space between the $L 4$ and $L 5$ vertebrae. 